\title{
An Off-Line Single-Inductor Multiple-Outputs LED Driver with High Dimming Precision and Full Dimming Range
}

Abstract - This paper presents a single-inductor multiple-outputs (SIMO) LED driver with precise dimming and full dimming range. Based on the coordination of a string-level and a system-level dimming schemes, the proposed SIMO LED driver can overcome practical constraints of existing SIMO LED drivers such as limited dimming range and needs for high-current switches. The proposal can achieve dimming precision up to an accuracy of $1 \%$ and also full dimming range. It has the flexibility of using either phase-shift or synchronous PWM switching for dimming control. The proposed circuit and control operations have been practically verified with a $25 \mathrm{~W}$ off-line SIMO driven LED system. Practical evaluations of its power quality and energy efficiency are also provided.

\section{INTRODUCTION}

LED technology involves complex interactions of heat, light, power and color. Dimming LED systems alters the power and thus the junction temperature and color spectra of the LED devices. Recent breakthroughs in the LED technologies have led to more understanding of these complex issues [1]-[5]. In order to make use of these technological advancements, there is a corresponding need for designing low-cost LED drivers to implement such precise color control and dimming control. Color-mixing and dimming LED systems usually require multiple LED strings [1]-[4]. LED drivers with multiple outputs that have independent output current control are needed. A typical circuit structure of an AC-powered multi-channel LED driver comprises (i) a front-end AC/DC conversion stage and (ii) a secondary multiple post-currentregulator stage [5]-[12]. The post-current-regulator can be a linear type current regulator or switch mode converter. With this two-stage configuration, it is difficult to design an LED driver that can concurrently 
achieve small form factor, low cost and high power efficiency, especially if the system comprises a high number of LED strings.

To achieve these advantageous features, a single-stage non-isolated LED driver with AC input and multiple DC outputs has been devised [13]. The LED driver involves a single-inductor-multiple-output (SIMO) structure (Fig. 1(a)). It can be viewed as an integrated version of multiple buck power-factorcorrection (PFC) converters (Fig. 1(b)). By sharing the main inductor $L$, the main switch $Q$ and the freewheeling diode $D_{a}$ among the power channels in Fig. 1(b), the total component count and thus total device losses could be significantly reduced. It is important to note that the power delivered to each channel of the SIMO LED driver can be individually controlled, provided that the dynamics of among these channels are fully decoupled. This can be realized by operating the driver in discontinuous conduction mode and by employing a time-multiplexing control scheme. In this way, the power channels will be enabled in a nonoverlapping fashion without cross-interference [13]-[16].

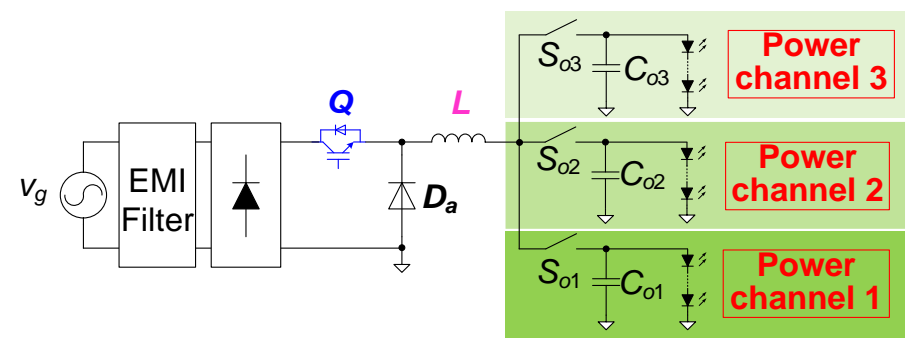

(a)

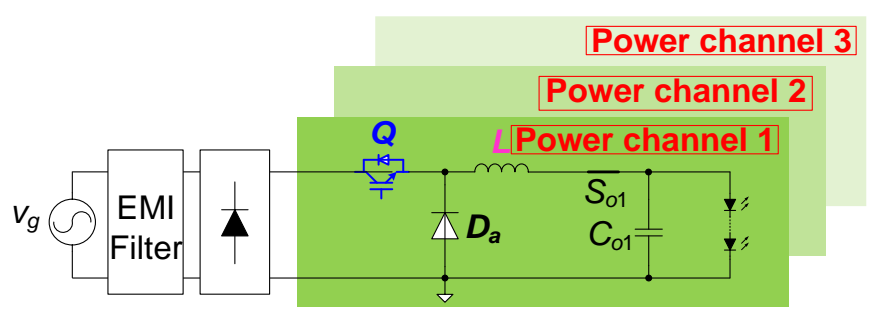

(b)

Fig. 1. Schematic diagrams of (a) an AC-powered single-inductor-multiple-output LED driver [18] and (b) its electrical equivalent.

Traditional dimming approaches include at least the analog and $P W M$ methods. Similar to the conventional buck PFC converter, precise and full-range analog dimming in each power channel (or LED string) can be difficult with the SIMO LED driver. The reason is that the steady-state duty cycle of the main switch $Q$ is very small due to the high step-down conversion ratio (e.g. from 110 Vrms AC to $20 \mathrm{~V} \mathrm{DC}$ ). As a result, the output current is very sensitive to the control signal which may be difficult to control. The power efficiency of analog dimming decreases as the dimming ratio becomes very small [13]. In 
comparison, the PWM dimming approach can achieve accurate and full-range dimming relatively easily because the average output current of the driver is a linear function of the dimming ratio. Moreover, since each power channel always operates under the full-load condition when the LED string is fully turned on and consumes no power when the string is turned off, the LED driver is expected to have a constant power efficiency for any dimming ratio. This interesting feature has been successfully demonstrated in a DC/DC three-channel resonant converter as reported in [17].

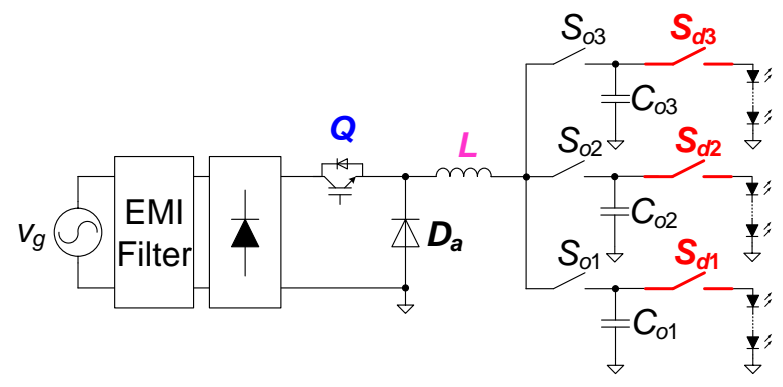

Fig. 2. Schematic diagrams of the proposed AC-powered SIMO LED driver with PWM dimming capability.

In this paper, an AC-powered SIMO LED driver with PWM dimming capability as shown in Fig. 2 is proposed. As compared with the SIMO driver shown in Fig. 1(a), the new SIMO driver includes three extra dimming switches $S_{d 1}-S_{d 3}$ which are connected in series with the respective LED loads. Its operations are based on the combined use of two control schemes at the string-level (i.e., when only one power channel is considered) and at the system-level (i.e., when all the power channels are considered). It will be shown that the proposal can avoid some existing problems of existing SIMO LED drivers such as limited dimming range and the requirements of high current ratings for power switches. Experimental prototype of $25 \mathrm{~W}$ has been constructed to realize the (i) precise dimming (1\% dimming precision) and (ii) full range dimming (i.e., 0\%-100\%). The flexibility of using various dimming methods for the string-level (e.g. PWM dimming, analog dimming or both) and system-level (e.g. synchronous and phase-shift) is also demonstrated. 


\section{STRING-LEVEL PWM DIMMING IN A SIMO LED DRIVER}

\section{A. Issues of Conventional String-Level PWM Dimming}

String-level PWM dimming is related to the control of the main switch $Q$ and the dimming switch (e.g. $\left.S_{d 1}\right)$ within a power channel. If only one channel of Fig.1(b) is considered, conventional PWM dimming scheme does not require the extra dimming switch $\left(S_{d 1}-S_{d 3}\right)$ in Fig.2. It achieves PWM dimming by switching the current reference of the converter between $I_{r e f}$ and zero [11], [18]. However, the slow slew-rate of the output current (due to the slow dynamics of the converter) during the PWM dimming will substantially limit the dimming frequency of the system (e.g. down to $100 \mathrm{~Hz}$ ) and the dimming ratio (e.g. higher than $20 \%$ and lower than $80 \%$ ) [18]. High quality and full-range PWM dimming are difficult to attain with the traditional PWM method.

Another string-level PWM dimming scheme, referred to as the PWM series dimming [18], is considered here. Power channel 1 (i.e., string 1) is selected as an example to highlight the issues associated with this approach if it is applied to the new SIMO LED driver. To simplify the analysis, the input voltage $v_{g}$ is assumed constant and denoted as $V_{G}$. However, the analysis can be extended to the general case where $v_{g}$ is a rectified sinusoidal signal if necessary.

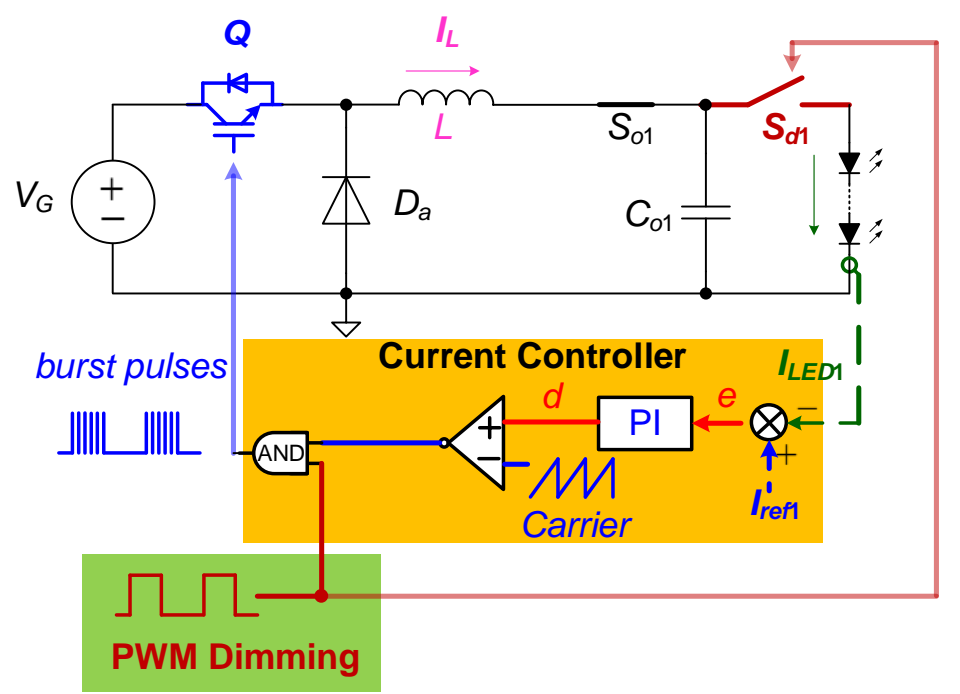

(a)

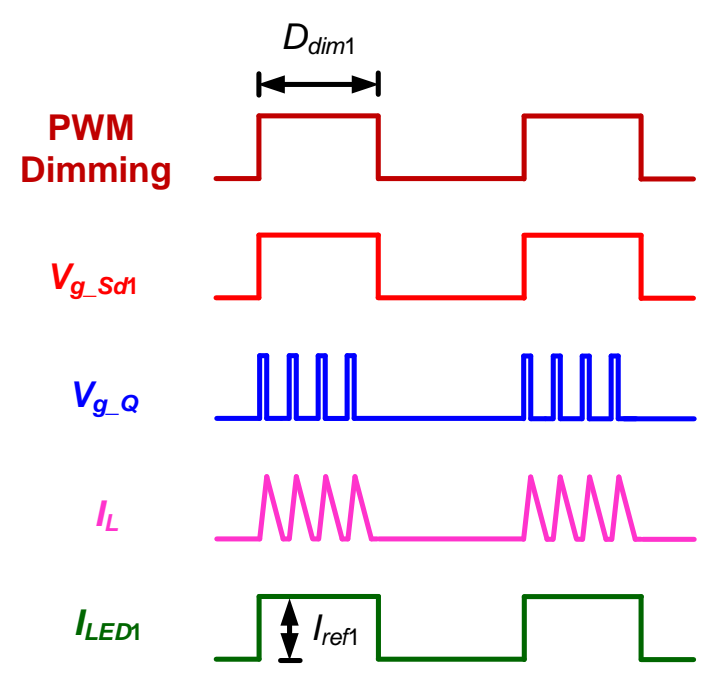

(b) 
Fig. 3. (a) Conventional PWM series dimming control scheme on power channel 1 and (b) the ideal operation waveforms.

Fig. 3(a) shows a conventional PWM series dimming control scheme for power channel 1 . The ideal operating waveforms are illustrated in Fig. 3(b). The main switch $Q$ is actively switching at a high frequency during the ON period of the PWM dimming signal (i.e., when the dimming switch $S_{d 1}$ is ON) in order to provide a constant and regulated current (at $I_{\text {ref } 1}$ ) in string 1 . When the PWM dimming signal is OFF, both $S_{d 1}$ and $Q$ are OFF, and the string current becomes zero. Apparently, the ideal output current $I_{L E D 1}$ has a PWM waveform and its average value can be precisely controlled by the duty cycle of the dimming signal $\left(D_{\operatorname{dim} 1}\right)$, i.e.,

$$
\bar{I}_{L E D 1}=I_{r e f 1} \times D_{\text {dim } 1} .
$$

where tis the averaging operator over a dimming period. $D_{\operatorname{dim} 1}$ can be set theoretically at $0 \%-100 \%$ to achieve a full dimming range.

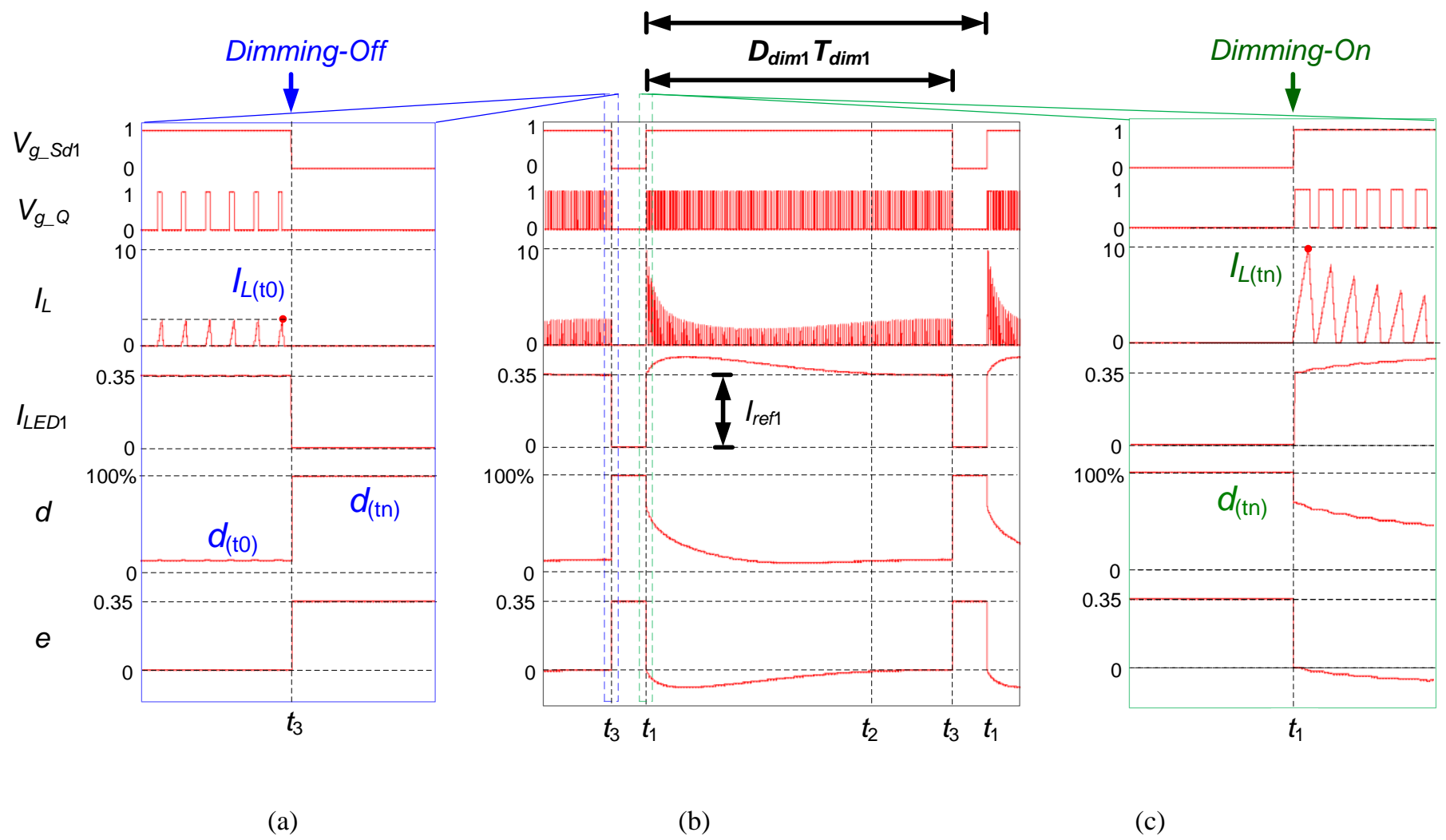


Fig. 4. Simulation waveforms of power channel 1 when conventional PWM series dimming control is employed ((a) enlarged view at the dimming-OFF instant (b) overview and (c) enlarged view at the dimming-ON instant).

In practice, it is difficult to obtain a perfect PWM current waveform for $I_{L E D 1}$ that has a sharp rising/falling edge without overshoot/undershoot. This can be observed from the simulation waveforms shown in Fig. 4(b). When the PWM dimming signal is turned ON at $t_{1}, I_{L E D 1}$ is not instantly settled at the reference value $I_{\text {ref } 1}=0.35$ until $t_{2}$. In particular, there is an overshoot in $I_{L E D 1}$ after $t_{1}$. A closer examination of Fig. 4(b) reveals that the inductor current $I_{L}$ has a similar trend: $I_{L}$ peaks at the dimming-ON instant and then gradually settles to its steady state. Based on these observations, it can be concluded that

(i) The average output current cannot be precisely controlled due to the overshoot in $I_{L E D 1}$, i.e.,

$$
\bar{I}_{L E D 1} \neq I_{\text {ref } 1} \times D_{\text {dim } 1}
$$

(ii) High current ratings for the switches, diodes and inductors are needed due to the current spikes of $I_{L}$;

(iii) Significant EMI noise introduced by the current spikes of $I_{L}$ could be generated;

(iv) Low dimming level and high dimming frequency $f_{\text {dim }}$ may not be achieved due to the finite settling time $T_{\text {settle }}$, because the dimming signal can only be OFF (e.g. at $t_{3}$ ) until $I_{L E D 1}$ has settled. Mathematically, $D_{\operatorname{dim} 1}$ and $f_{\text {dim }}$ must satisfy

$$
\frac{D_{\text {dim } 1}}{f_{\text {dim }}}=t_{3}-t_{1} \geq t_{2}-t_{1}=T_{\text {setle }}>0 \text {. }
$$

Due to the aforementioned issues, the PWM series dimming approach, like the conventional PWM dimming, is incapable of performing full range and precise dimming that are desired for the proposed ACpowered SIMO LED driver.

To further analyze this transient effect, an enlarged view of Fig. 4(b) at the dimming-OFF and -ON instants are shown in Fig. 4(a) and (c), respectively. It can be seen that, before the dimming OFF signal is applied at $t_{3}$, a steady-state operation has been reached and the error $e$ between $I_{\text {ref } 1}$ and $I_{L E D 1}$ is zero. The 
output of the PI compensator $d$ is thus constant $\left(d_{(\mathrm{tn})}\right)$ and $I_{L}$ reaches a constant peak value $I_{L(\mathrm{t} 0)}$. As a result, a constant power is delivered to the output and the output current $I_{L E D 1}$ is constant at $0.35 \mathrm{~A}$. When the dimming signal is OFF at $t_{3}$, the dimming switch is turned off. $I_{L E D 1}$ becomes zero and the error $\left(I_{r e f 1}-I_{L E D 1}\right)$ is a non-zero. The PI output will therefore increase and deviate from its steady-state value $\left(d_{(t n)} \neq d_{(t 0))}\right)$. In the simulation, the time constant of the PI compensator is chosen to be very small to ensure fast reference tracking. The output of the PI compensator therefore increases quickly.

The undesired deviation of $d$ will aggravate the LED dimming performance at $t_{1}$ as the string is turned back on. As shown in Fig. 4(c), the initial output current $I_{L E D 1}$ is still 0.35 A, because the voltage of the output capacitor $C_{o 1}\left(V_{C o 1}\right)$ is not discharged during the dimming-OFF period and is equal to the steady-state value $\left(V_{C o 1(\text { steady-state) })}\right)$. The initial error $\left(I_{r e f 1}-I_{L E D 1}\right)$ is thus zero. However, the initial PI output will be $d_{t n}$. A larger $d_{t n}$ indicates that the inductor current will be increased for a longer period of time, and the peak inductor current will reach a much higher value $I_{L(\mathrm{tn})}$. As a result, more power will be transferred to the output than required and the output voltage/current will also increase. The dynamics of the output voltage/current is the response of the $C_{o 1}$-LED network to inductor current pulses with the initial conditions of $V_{C o 1}=V_{C o 1(\text { steady-state) }}$.

To ensure a stable LED current as the string is turned on, conventional solutions are to employ a linear current regulator in series with the LED load [5], [12], [19]-[21], or to increase the output capacitance $C_{o 1}$ of the driver The former solution, however, is not power efficient due to the power losses in the linear regulators; the latter solution will reduce the natural frequency of the system and will further increase the system’s settling time. 


\section{B. Instant Duty Restoration Technique for High Performance String-Level PWM Dimming}

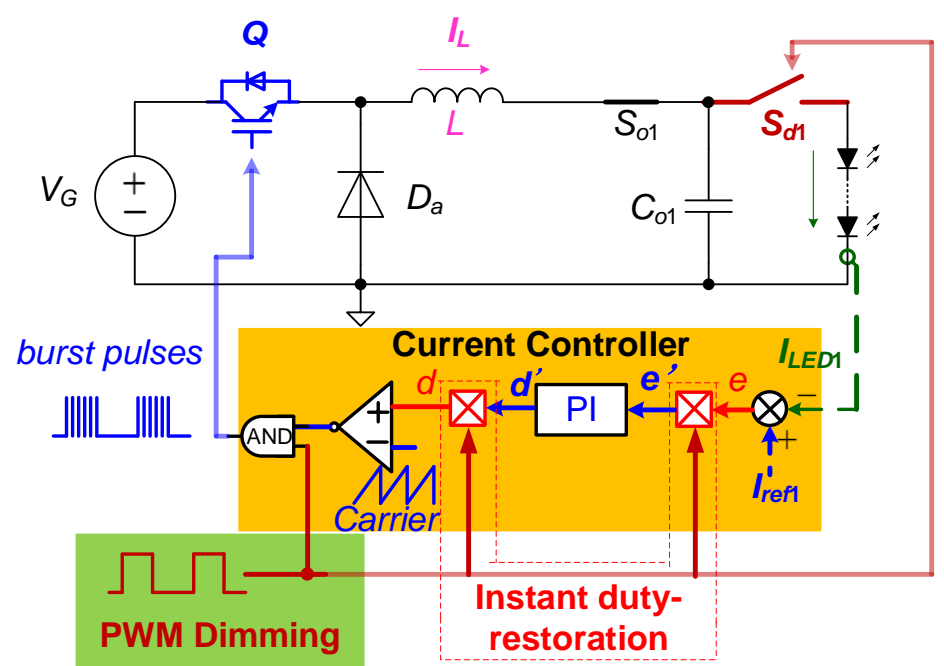

Fig. 5. PWM series dimming control with the proposed instant-duty-restoration technique on power channel 1.

To resolve the aforementioned duty cycle deviation issue, an instant-duty-restoration (IDR) technique as shown in Fig. 5 is proposed. Compared with the control scheme depicted in Fig. 3(a), the new control scheme is augmented with two multiplying operations. Whenever the PWM dimming signal is turned OFF, the multiplying operation will always force the new error signal $e^{\prime}$ (which is the input of the PI compensator) to zero, regardless of the value of $e$. This will cause the output $d$ ' of the PI compensator to remain constant and to stay at the steady-state value. In other words, the steady-state value of $d$ is memorized by the variable $d$ '. On the other hand, to securely shut down the whole system during the dimming-OFF period, the actual duty cycle $d$ will be forced to zero by the second multiplying operation of $d^{\prime}$ and the dimming signal.

As the dimming signal is turned $\mathrm{ON}, d^{\prime}=d$ and $e^{\prime}=e$. Therefore, $d$ is instantly restored to the steadystate value stored in $d^{\prime}$. The initial error $e$ should be zero because $I_{L E D}$ is equal to $I_{r e f 1}$. The steady-state value of $d$ causes $I_{L}$ to change to the desired value of $I_{L(\mathrm{t} 0)}$. The instantaneous power transferred to the output will therefore be equal to the actual loading requirement instantly, and the output voltage/current will remain constant. In this way, the system can always operate normally during the system's dimming-ON and -OFF period without causing any transient oscillation. 
Fig. 6 shows the simulation waveforms of power channel 1 with the IDR technique. By forcing the input

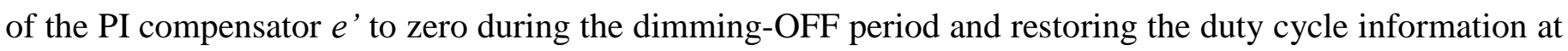
the dimming-ON instant, both the inductor current and the output current are immediately settled at their respective steady-state values as the dimming signal is turned $\mathrm{ON}$. This will lead to a flat ON-state current for $I_{L E D 1}$. As a result, the light intensity of the LED string can be controlled with high precision over the full dimming range. With the high performance dimming capability, a power channel is able to flexibly perform the three most popular string-level dimming schemes, i.e., the analog dimming, PWM dimming and hybridanalog-PWM dimming.

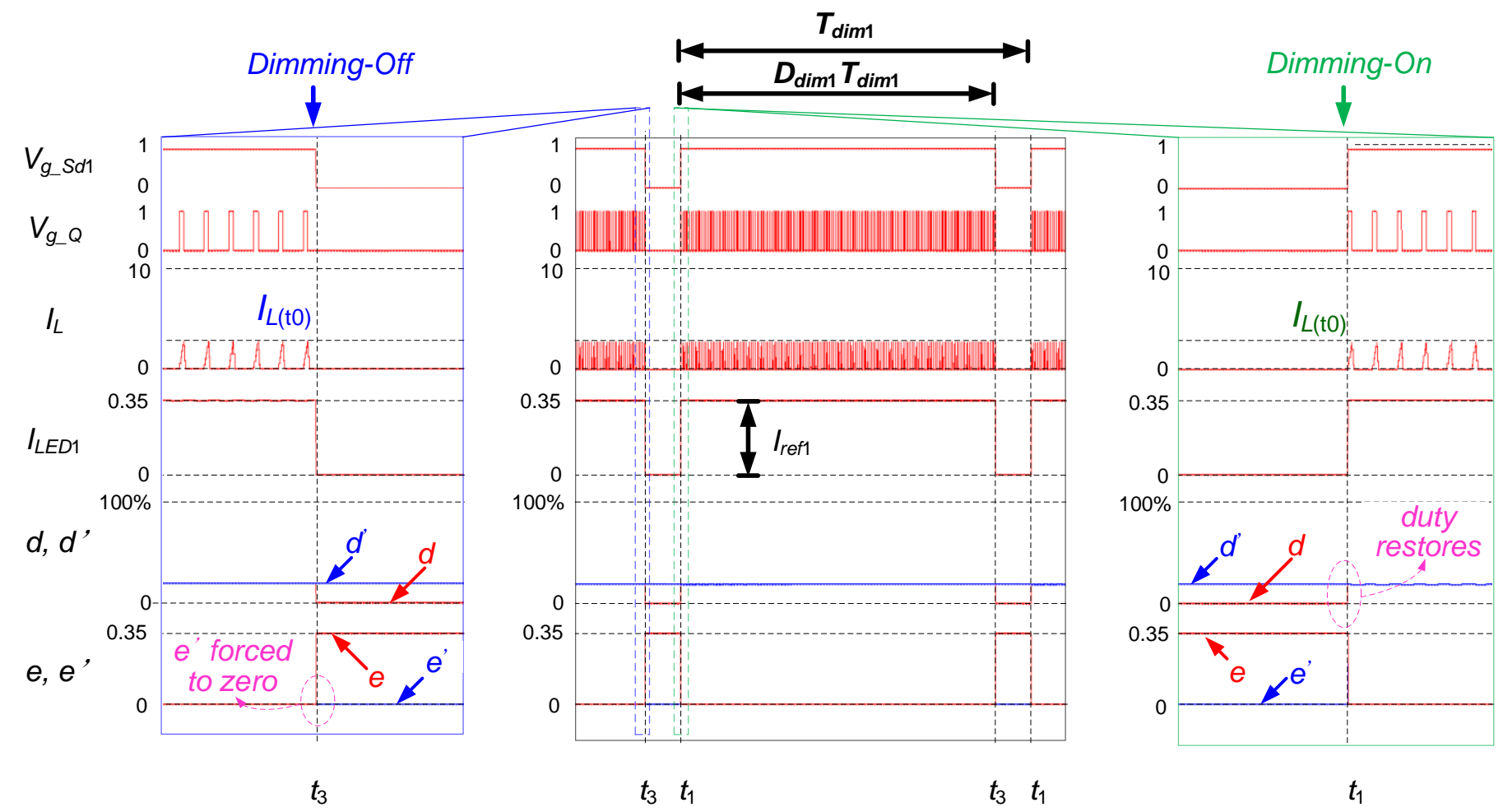

Fig. 6. Simulation waveforms of power channel 1 when the instant-duty-restoration technique is employed ((a) enlarged view at the dimming-OFF instant (b) overview and (c) enlarged view at the dimming-ON instant). 


\section{SYSTEM-LEVEL PWM DIMMING IN A SIMO LED DRIVER}

\section{A. Issues of Conventional System-Level PWM Dimming}

System-level PWM dimming is related to the coordinated control of the power channels, i.e., the control over the power-channel-selection switches $\left(S_{o 1}-S_{o 3}\right)$ and the dimming switches $\left(S_{d 1}-S_{d 3}\right)$. Due to the nonoverlapping (time-multiplexing) operation of the power channels, system-level PWM dimming can be challenging.

Fig. 7 illustrates two possible system-level dimming approaches that have been reported for a threeoutput DC-DC LED driver with independent output regulation. Fig. 7(a) illustrates the low-frequencysequential (LFS) dimming technique that is proposed for RGB backlighting applications [12] [22][23]. The three power channels are enabled in a phase-shift manner by consecutively turning on $S_{o 1}-S_{o 3}$ in a repeated

fashion. A dimming switch can be turned on once its power channel is enabled. Based on this dimming control, the output currents will have a PWM frequency of $f_{\operatorname{dim}}=1 / T_{\operatorname{dim}}$ (where $T_{\operatorname{dim}}$ is the dimming period) which is the same as that of the dimming signal. Normally, $f_{\text {dim }}$ is much lower than the switching frequency $f_{s}$ of the main switch $Q$. For instance, $f_{\text {dim }}$ can be set at $200 \mathrm{~Hz}$ to avoid noticeable flicker issues [24]. The LFS dimming technique is simple and easy to implement. However, since each power-channel-selection switch is turned $\mathrm{ON}$ for a period of $T_{\mathrm{dim}} / 3$, the dimming ratio for each string will be constrained by

$$
0 \leq D_{\operatorname{dim} 1}, D_{\operatorname{dim} 2}, D_{\operatorname{dim} 3} \leq \frac{1}{3}
$$

Therefore, full dimming range cannot be achieved among the strings. As the number of strings (power channels) increases, the dimming ratio per power channel will be constrained by $1 / N$, where $N$ is the number of the strings. 


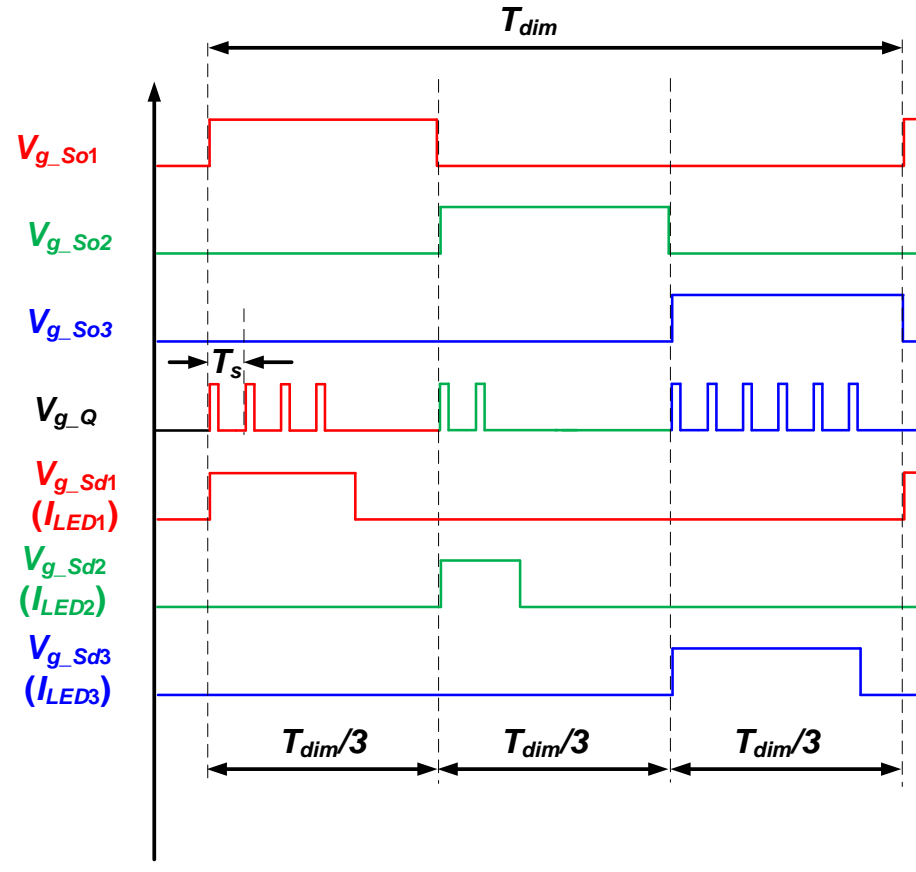

(a)

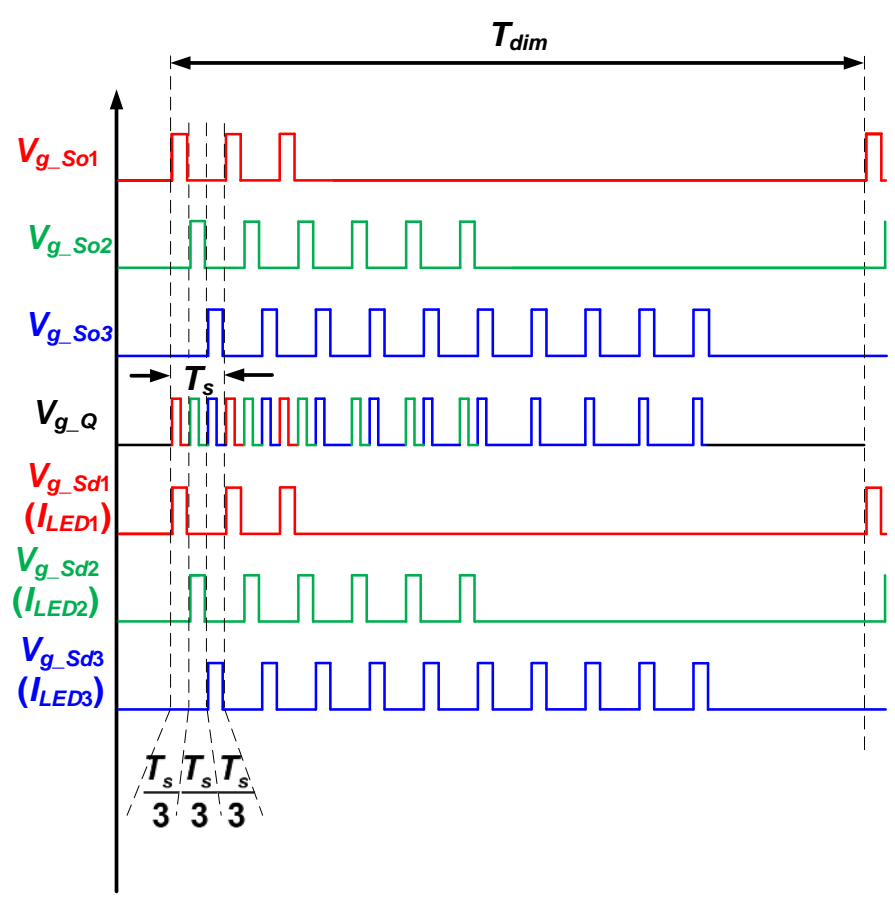

(b)

Fig. 7. Timing diagrams of (a) the low-frequency-sequential (LFS) PWM dimming technique and (b) the high-frequency-timesharing (HFTS) PWM dimming technique.

To achieve full-range PWM dimming among the strings, a high-frequency-time-sharing (HFTS) dimming technique with timing diagram as shown in Fig. 7(b) has been proposed [15]. For HFTS dimming, the three power channels are enabled by turning on $S_{o 1}-S_{03}$ in a time-sharing manner over a switching period $T_{s}$. Each channel is active for a period of $T_{\mathrm{s}} / 3$ [15]. Like the LFS approach, a dimming switch can be turned on when the associated power channel is active. However, due to the enabling patterns of the power channels, the output currents will be of high-frequency PWM pulse trains. Dimming through the control of the output currents is achieved by increasing/decreasing the number of the pulse trains within $T_{d i m}$. However, due to the pulsating nature of the output currents, the ON-state LED currents will be thrice (i.e., $3 I_{o 1}, 3 I_{o 2}$, $3 I_{o 3}$ ) that of the LFS dimming technique (i.e., $\left.I_{o 1}, I_{o 2}, I_{o 3}\right)$ in order to produce the same light output. Similarly, for an $N$-string SIMO LED driver, the current ratings of the LED devices will be $N I_{o 1}, N I_{o 2}, N I_{o 3}$, etc. Therefore, the HFTS dimming technique requires the use of LED devices with high-current ratings. 


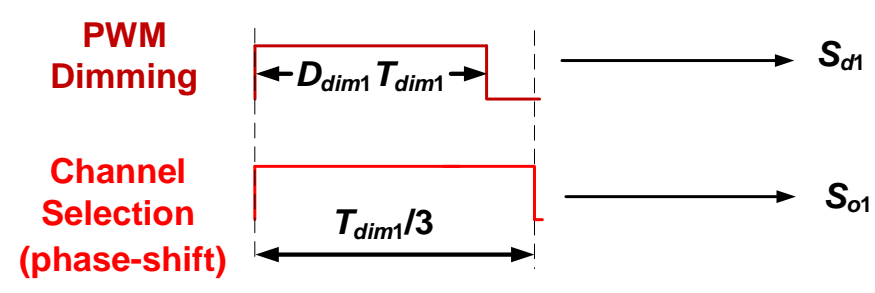

(a)

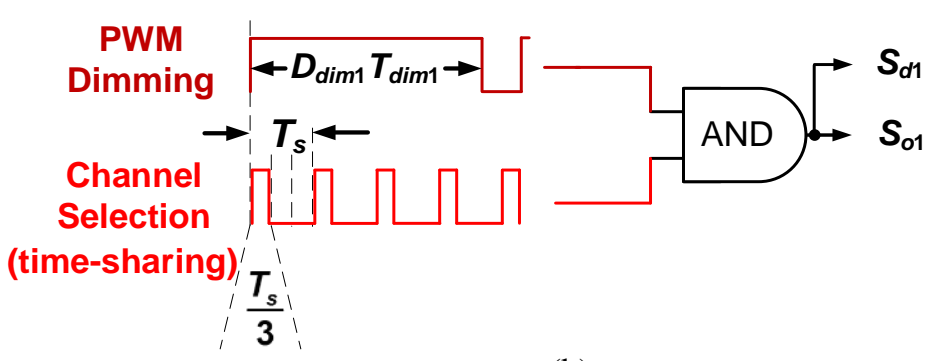

(b)

Fig. 8. Gate generation method for (a) the low-frequency-sequential (LFS) PWM dimming technique and (b) the high-frequencytime-sharing (HFTS) PWM dimming technique.

Fig. 8 illustrates the possible gate signal generation scheme for the dimming switches and the powerchannel-selection switches used in the LFS and HFTS dimming technique. In both methods, the ON-periods of the dimming switches are always less than or equal to that of the non-overlapping power-channelselection switches. As a result, the dimming switches are also operated in a non-overlapping manner.

\section{B. Coordinated Low-Frequency and Time-Sharing Dimming Technique for System-Level High}

\section{Performance PWM Dimming}

A coordinated low-frequency and time-sharing (CLFTS) technique is proposed in this paper to address the aforementioned issues. Fig. 9 (a) and (b) show the timing diagrams of the corresponding switches in performing in synchronous PWM dimming and phase-shift dimming, respectively. In both scenarios, the three dimming switches are operating at a low frequency while the three power-channel-selection switches are operating at high frequency in a time sharing arrangement with one another per switching period. Clearly, the CLFTS technique successfully combines the advantages of the LFS and HFTS techniques:

1. The high-frequency time-sharing operation of the power-channel-selection switches enables a full range dimming among the strings.

2. The low-frequency dimming switches lead to a non-pulsating output current profile for each string during the dimming-ON period.

3. The use of LED devices with low current ratings is feasible. 


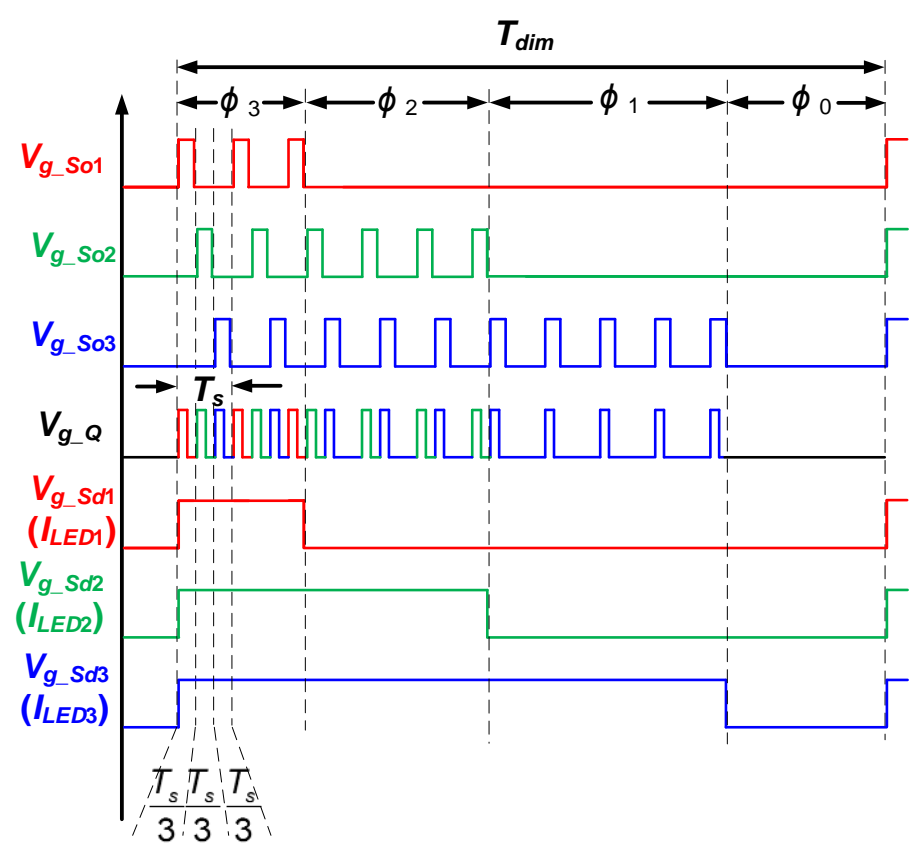

(a)

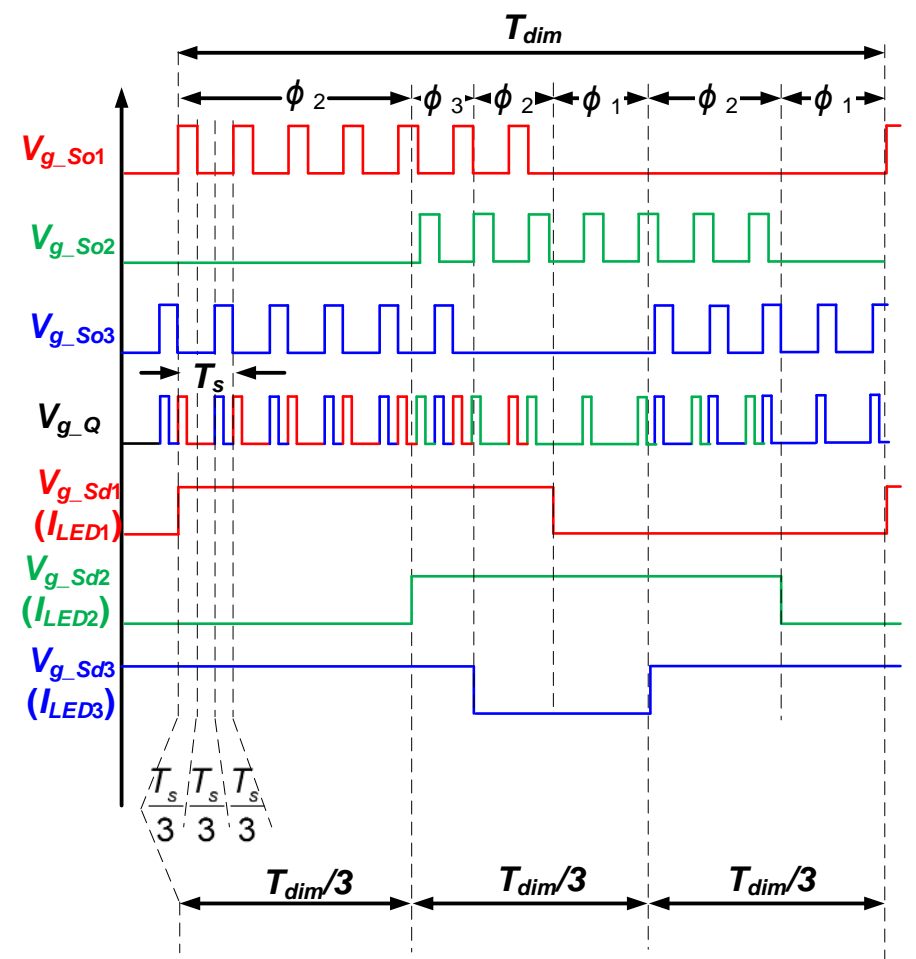

(b)

Fig. 9. Timing diagrams of the proposed low-frequency-and-time-sharing-coordinated (LFTSC) PWM dimming technique in performing (a) synchronous dimming and (b) phase-shift dimming.

The main advantage of the CLFTS dimming technique is that the dimming switch in the SIMO LED driver can be turned on even if the associated power channel is deactivated. This is possible because the output capacitor can continue to supply power to the LED load in that power channel. The LED current will not interfere with nor be interfered by the operation of the other power channels. In other words, the ONperiod of a dimming switch does not have to be less than or equal to that of the associated power-channelselection switch. Overlapping operation of the dimming switches is no longer a problem. With three dimming switches, the LED driver has four operation modes $\left(\phi_{0}-\phi_{3}\right)$ (Fig. 9). The numeric subscript refers to the number of active power channels per switching period $T_{s}$. For example, $\phi_{0}$ signifies that no power channels are activated during $T_{s}$, while $\phi_{1}$ means that only one out of the three power channels is enabled. 


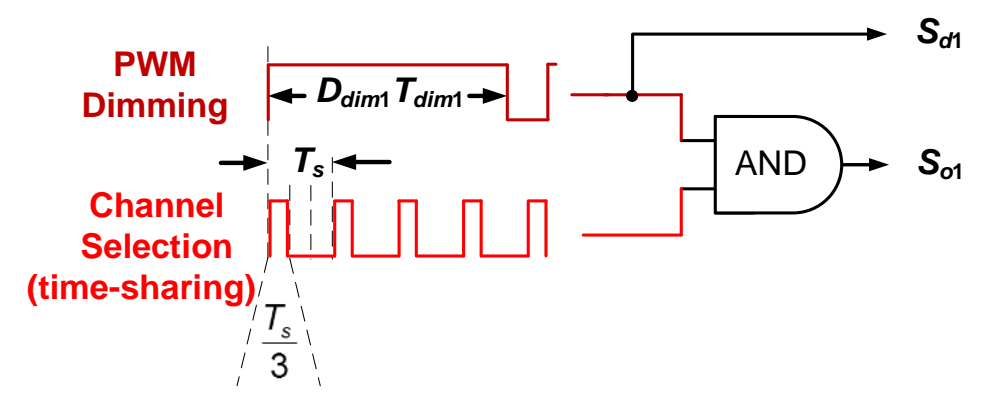

Fig. 10. Gate generation method for the proposed low-frequency-and-time-sharing-coordinated (LFTSC) PWM dimming technique.

The gate signal generation method for the dimming switches and the power-channel-selection switches is illustrated in Fig. 10. Detailed comparisons of the CLFTS dimming technique versus the conventional system-level PWM dimming techniques are summarized in Table I.

Table. I. A comparison of the various system-level dimming techniques (LFS, HFTS and LFTSC).

\begin{tabular}{|c|c|c|c|c|}
\hline & $\begin{array}{c}\text { Frequencies of } \\
\text { Dimming switches } \\
S_{d 1}-S_{d 3}\end{array}$ & $\begin{array}{c}\text { Frequencies of power- } \\
\text { channel-selection switches } \\
S_{o 1}-S_{o 3}\end{array}$ & $\begin{array}{c}\text { ON-state LED } \\
\text { currents for } \\
I_{L E D 1}-I_{L E D 3}\end{array}$ & $\begin{array}{c}\text { Dimming } \\
\text { ranges for } \\
D_{\text {dim1 }}-D_{\text {dim3 }}\end{array}$ \\
\hline $\begin{array}{c}\text { Low-frequency sequential } \\
\text { (LFS) }\end{array}$ & $f_{\text {dim }}$ (Low) & $f_{\text {dim }}($ Low $)$ & Continuous & $0 \%-33.3 \%$ \\
\hline $\begin{array}{c}\text { High-frequency-time-sharing } \\
\text { (HFTS) }\end{array}$ & $f_{\mathrm{s}}(\mathrm{High})$ & $f_{\mathrm{s}}(\mathrm{High})$ & $\begin{array}{c}\text { High frequency } \\
\text { PWM Pulses }(\text { with } \\
\text { duty cycle of } 1 / 3)\end{array}$ & $0 \%-100 \%$ \\
\hline $\begin{array}{c}\text { Coordinated Low-frequency- } \\
\text { and-time-sharing (CLFTS) }\end{array}$ & $f_{\mathrm{dim}}$ (Low) & $f_{\mathrm{s}}(\mathrm{High})$ & Continuous & $0 \%-100 \%$ \\
\hline
\end{tabular}

\section{PERFORMANCE Evaluation}

The proposed IDR technique (for string-level dimming) and CLFTS dimming technique (for system-level dimming) are verified with a $25 \mathrm{~W}$ AC-powered SIMO LED driver prototype with 3 strings as shown in Fig. 11. The circuit schematic is shown in Fig. 12. The circuit parameters can be chosen based on the design principle described in [13] and they are listed in Table II. The entire control part of the SIMO LED driver (MUX, the channel selection logic, PI compensators, = and the proposed string-level and system-level dimming techniques) is implemented with a TMS320F28069 Piccolo microcontroller. In Fig. 12, there are six control inputs, i.e., $I_{r e f 1}-I_{r e f 3}$ (for controlling the ON-state LED currents of string 1-3) and PWM1PWM3 (for controlling the respective dimming ratios). To demonstrate the string-level and system-level dimming performance of the LED driver, the six inputs are manually configured at different values and/or 
with different switching patterns. In practice, they may be controlled via an external color and flux control algorithms for a complete system design.

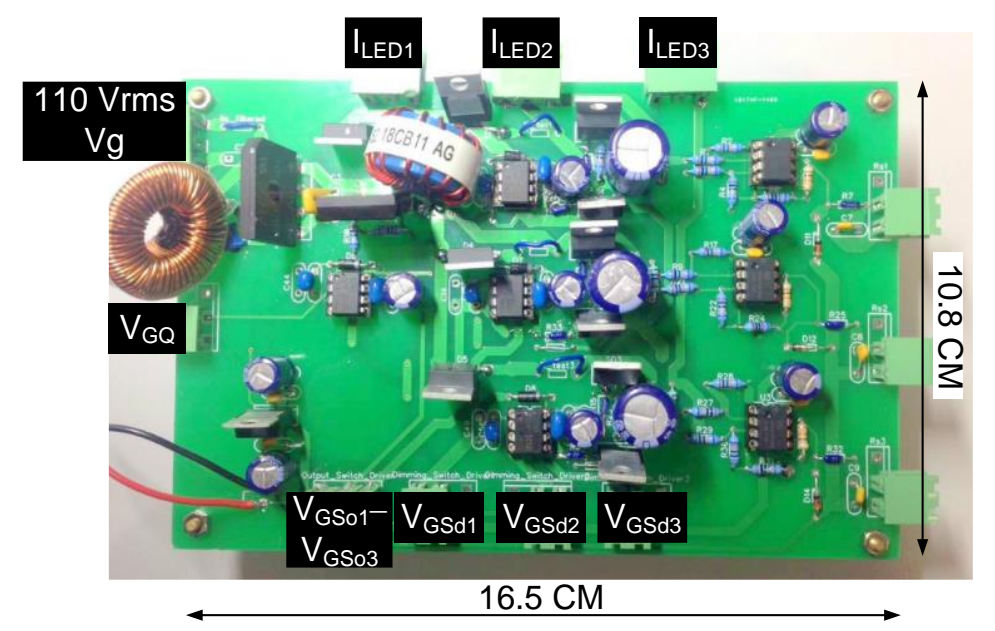

Fig. 11. The proposed dimmable AC-powered SIMO LED driver.

Table. II. Design Specifications of an Off-line SIMO LED Driver.

\begin{tabular}{c|c|c|c}
\hline \hline Design Parameter & Value & Component & Model No. \\
\hline \hline Input voltage $v_{g}$ & $110 \mathrm{Vrms} / 60 \mathrm{~Hz}$ & Diode Bridge Rectifier & GBU10G-BP \\
\hline EMI filter $\left(L_{f}, C_{f}\right)$ & $1 \mathrm{mH}, 0.1 \mu \mathrm{F}$ & Main Switch $Q$ & IPW50R280CE \\
\hline Output current ripple $\Delta i_{L E D}$ & $7 \%$ & MOSFET Gate Driver & IRS2101PBF \\
\hline Max. current ripple $\Delta i_{\text {Lmax }}$ & $6 \mathrm{~A}$ & $\begin{array}{c}\text { Freewheeling and Branch } \\
\text { Diodes }\end{array}$ & MUR1540G \\
\hline Main switch frequency $f_{s}$ & $99 \mathrm{kHz}$ & $\begin{array}{c}\text { Power-channel-selection } \\
\text { switches and dimming switches }\end{array}$ & IRFI4227PbF \\
\hline Dimming frequency $f_{\text {dim }}$ & $200 \mathrm{~Hz}$ & Output Capacitor $\left(C_{o 1}, C_{o 2}, C_{o 3}\right)$ & $\begin{array}{c}\text { UPX1V102MHD (long } \\
\text { lifetime) }\end{array}$ \\
\hline Output capacitance $\left(C_{o 1}, C_{o 2}, C_{o 3}\right)$ & $1000 \mu \mathrm{F}$ & LED for string 1 & 7 Red LEDs LUXEON \\
\hline Rated output currents $I_{L E D}$ & $350 \mathrm{~mA}$ & LED for string 2 & 7 Green LEDs LUXEON \\
\hline Main inductor $L$ & $5 \mu \mathrm{H}$ & LED for string 3 & 7 Blue LEDs LUXEON \\
\hline
\end{tabular}

\section{A. Practical Evaluation of String-Level Dimming}

In the first set of the experiments, the string-level dimming techniques are tested in string 1 . The other two strings are deactivated by setting the respective dimming ratios to zero. The ON-state current of string 1 is set at $0.35 \mathrm{~A}$. In order to compare the dynamic responses of the SIMO LED driver with and without the proposed IDR technique, the input of the driver is connected to a $110 \mathrm{~V}$ DC voltage source and the output capacitance is reduced to $33.3 \mu \mathrm{F}$. 


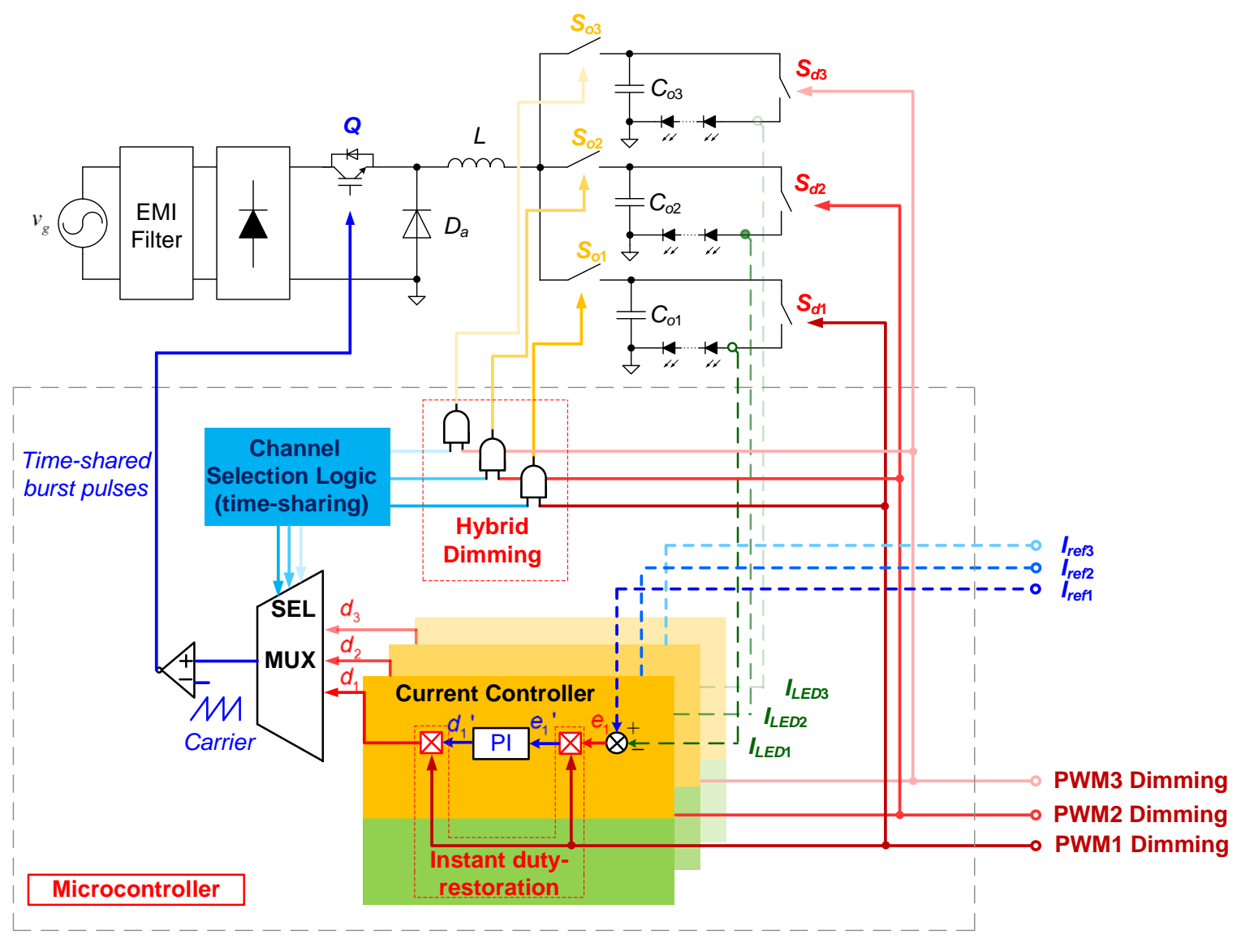

Fig. 12. Full schematic diagram of a dimmable AC-powered SIMO LED driver with the proposed instant-duty-restoration (IDR) and the low-frequency-and-time-sharing-coordinated (LFTSC) dimming technique.

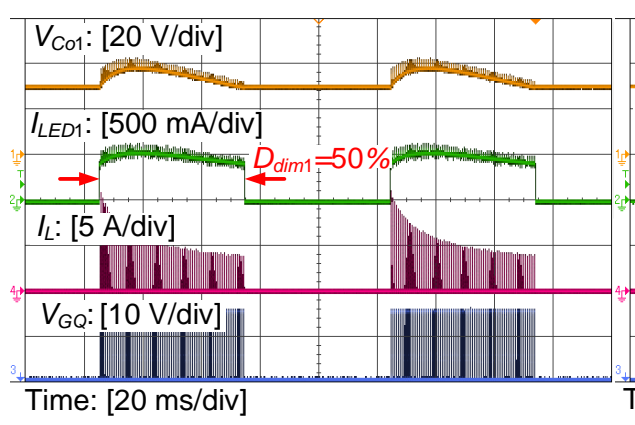

(a)

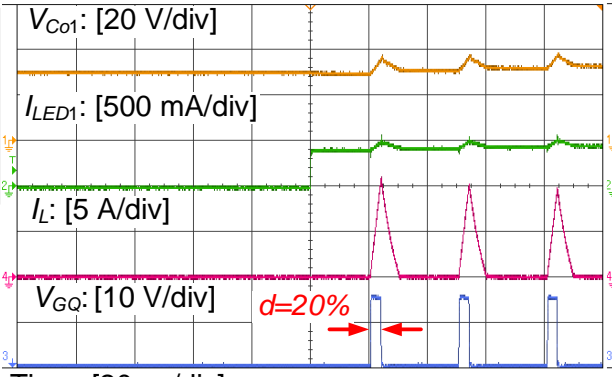

Time: [20 $\mu$ s/div]

(b)

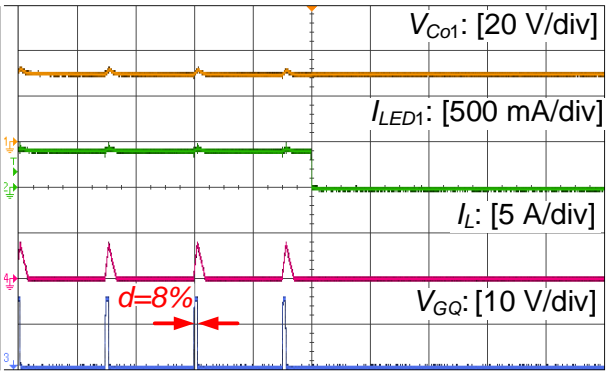

Time: $[20 \mu \mathrm{s} / \mathrm{div}]$

(c)

Fig. 13. Experimental waveforms of the proposed driver with the conventional PWM series dimming (50\% dimming) ((a) overview (b) enlarged view at the dimming-ON instant and (c) enlarged view at the dimming-OFF instant). 


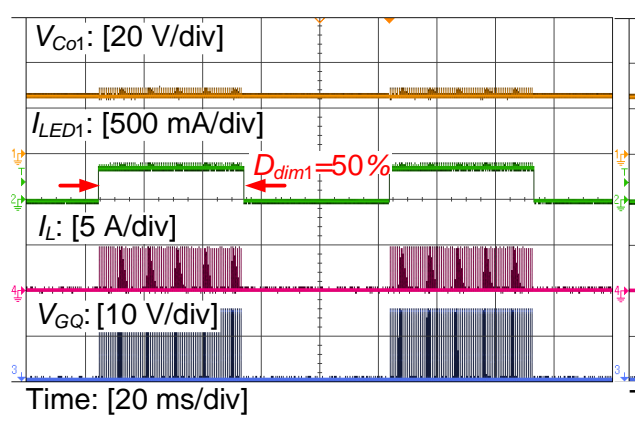

(a)

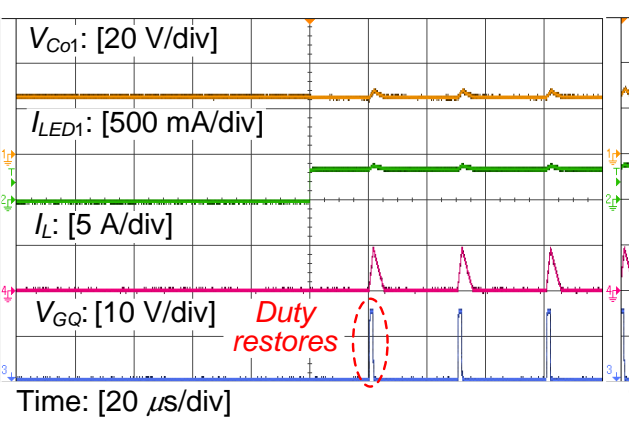

(b)

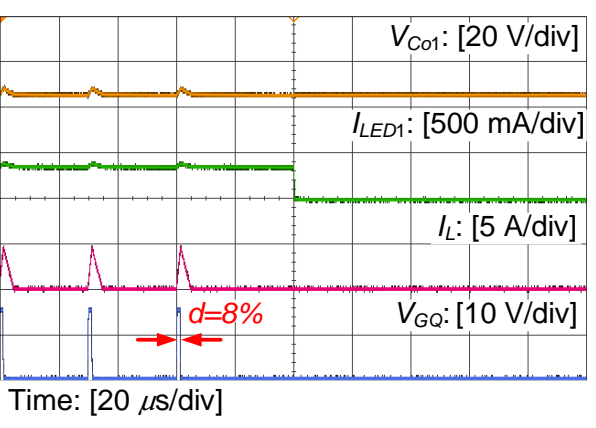

(c)

Fig. 14. Experimental waveforms of the proposed driver with the instant-duty-restoration (IDR) technique (50\% dimming) ((a) overview (b) enlarged view at the dimming-ON instant and (c) enlarged view at the dimming-OFF instant).

By adopting the conventional PWM series dimming technique (Fig. 13), a large current spike in the inductor current $i_{L}$ (up to $11.5 \mathrm{~A}$ ), an overshoot in the output voltage (up to $40 \mathrm{~V}$ ) and output current (up to 0.6 A) occur when the LED driver is switched from the idle state to the working state. As a result, the LED current cannot be precisely controlled and the LED driver will require the use of high current rating components in the design. Moreover, due to the long settling time of the LED voltage/current (2.36 ms, i.e., $47 \%$ of $T_{d i m}$ ), a dimming ratio below $47 \%$ cannot be achieved. The duty cycle deviation issue can be clearly observed in Fig. 13. In Fig. 13(b), the duty cycle of the first pulse of the main switch gate signal after the dimming-ON instant is nearly $20 \%$, while it is merely $8 \%$ for a steady-state operation as shown in Fig. 13(c).

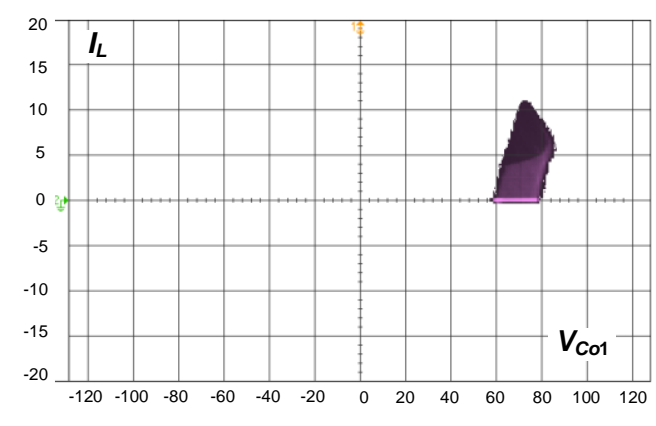

(a)

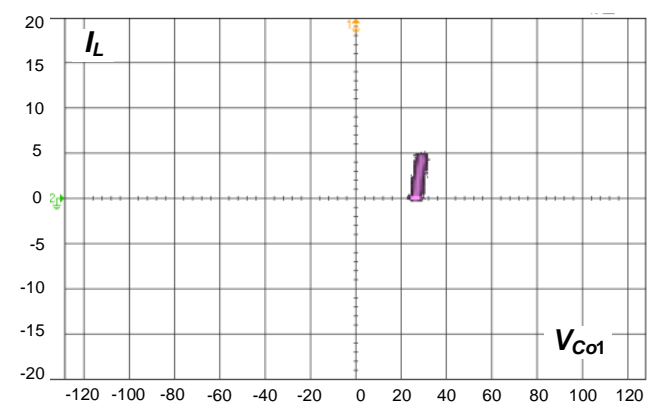

(b)

Fig. 15. The system state trajectories (a) with the conventional PWM series dimming and (b) with the proposed instant-dutyrestoration (IDR) technique (50\% dimming). 
Fig. 14 shows the measurements of the same experiment with the proposed IDR technique employed in the driver. As the LED driver starts to work from the idle state, the steady-state duty cycle $(8 \%)$ is immediately restored and the inductor current reaches the steady-state current level (5 A) with almost zero settling time. This leads to an LED current resembling an almost perfect PWM waveform. Fig. 15 shows a plot of the state trajectories of the inductor current $i_{L}$ versus the capacitor voltage $V_{C o 1}$ with and without the IDR technique. Clearly, the dynamic trajectory of the driver with the IDR technique is much cleaner (short vertical lines on state plane) as compared to that without the IDR technique (an irregular area on state plane representing oscillations).

Since there is no dynamic oscillation with the IDR technique, the LED current can be precisely controlled with a full dimming range. As illustrated in Fig. 16, the LED current can be accurately controlled even with a $1 \%$ dimming ratio.

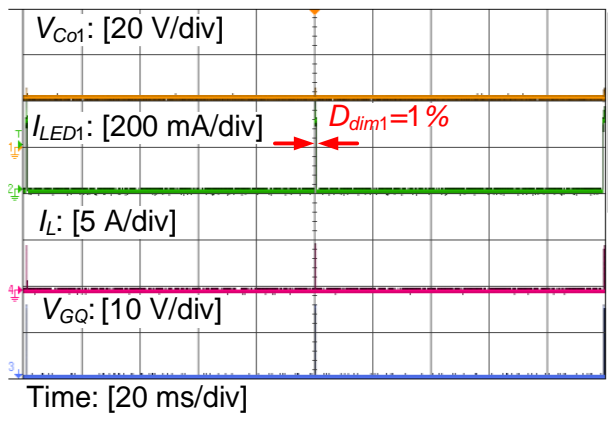

(a)

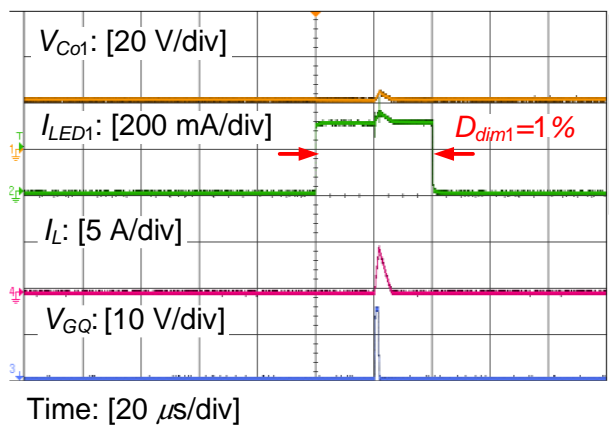

(b)

Fig. 16. Experimental waveforms of the proposed driver with the instant-duty-restoration technique (1\% dimming) ((a) overview (b) enlarged view)

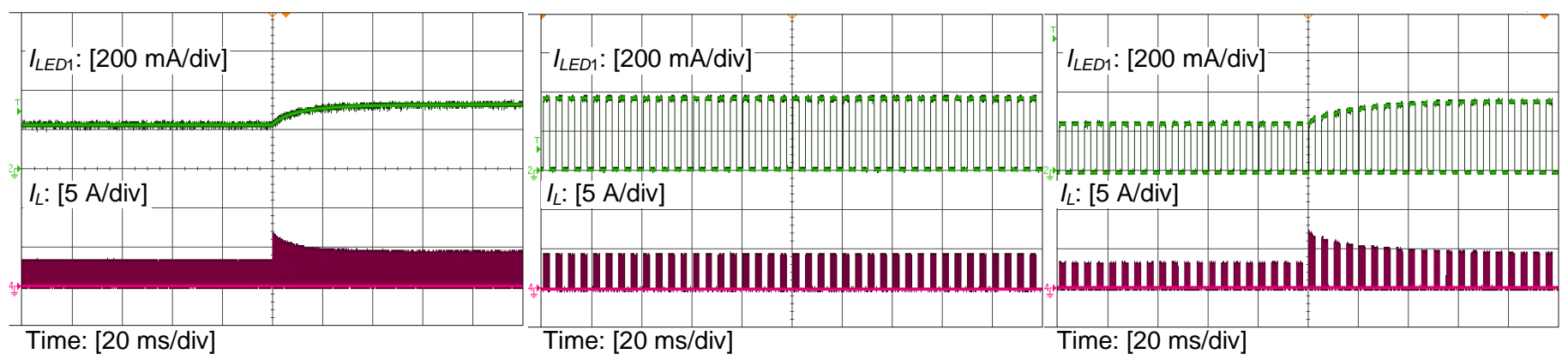

(a) (b) (c) 


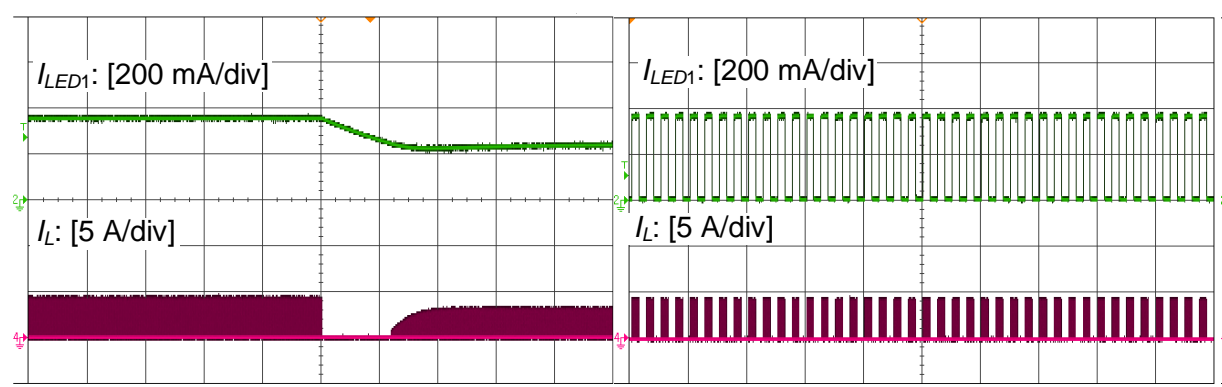

Time: [20 ms/div]

(d)

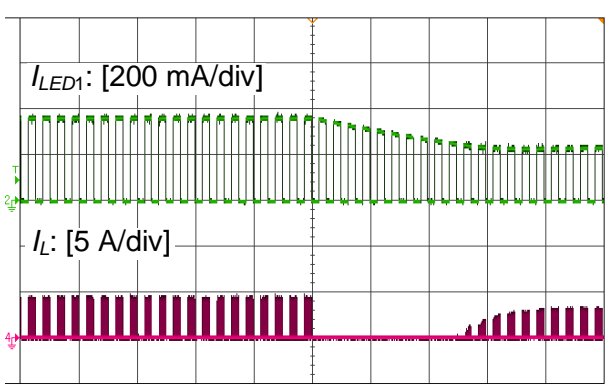

Time: [20 ms/div]

(f)

Fig. 17. Experimental waveforms of the proposed driver for (a) (d) analog dimming (from $250 \mathrm{~mA}$ to $350 \mathrm{~mA}$ and then from 350 $\mathrm{mA}$ to $250 \mathrm{~mA}$ ) (b) (e) PWM dimming (50\% dimming ratio) and (c) (f) hybrid analog-PWM dimming.

By employing the IDR technique, a SIMO LED driver can conveniently incorporate various string-level dimming schemes, e.g. analog dimming, PWM dimming or their combination. The flexibilities of performing the three dimming schemes are demonstrated through Fig. 17, which shows the waveforms of the output current and the inductor current of the driver under the respective schemes. In all scenarios, there is no oscillation in the inductor current or in LED current. The system response with respect to the change of the dimming command is less than $50 \mathrm{~ms}$. This is fast enough for most applications.

\section{B. System-Level Dimming Evaluation}

In the second set of experiments, the proposed CLFTS dimming technique is examined. In the experiments, the prototype is powered by an AC voltage source (Model number: AFC-500W) and the output capacitance for string 1 is changed back to the nominal value of $1000 \mu \mathrm{F}$.

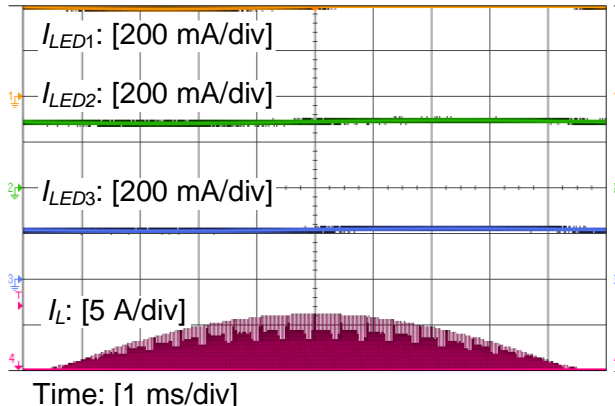

Time: [1 ms/div]

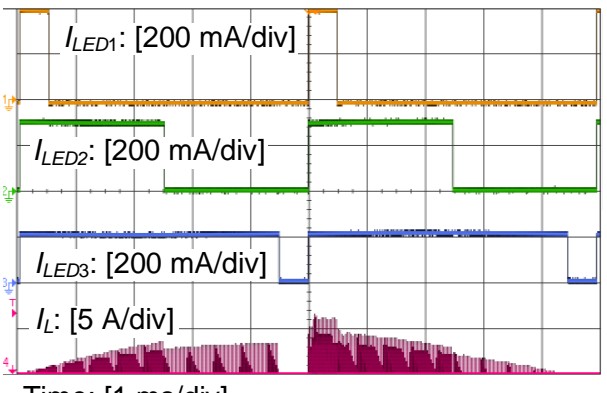

Time: [1 ms/div]

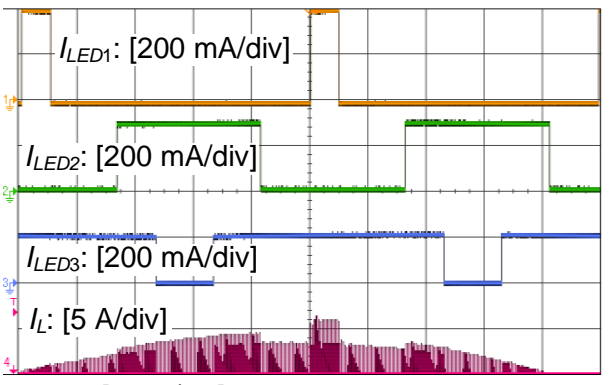

Time: [1 ms/div] 
Fig. 18. The measured output LED currents $\left(I_{L E D 1}, I_{L E D 2}, I_{L E D 3}\right)$ and the inductor current $\left(i_{L}\right)$ of the proposed driver with (a) no PWM dimming; (b) synchronous PWM dimming; and (c) phase-shift PWM dimming.

Fig. 18 shows the experimental waveforms of the inductor current $\left(i_{L}\right)$ and the three output currents $\left(I_{L E D 1}\right.$, $\left.I_{L E D 2}, I_{L E D 3}\right)$ of the proposed driver operating with (i) no PWM dimming, (ii) synchronous dimming and (iii) phase-shift dimming over half a line cycle. The ON-state LED current references $I_{r e f 1}, I_{r e f 2}, I_{r e f 3}$ are set at 400 $\mathrm{mA}, 300 \mathrm{~mA}$ and $200 \mathrm{~mA}$, respectively, and the dimming ratios $D_{\operatorname{dim} 1}, D_{\operatorname{dim} 2}, D_{\operatorname{dim} 3}$ (for synchronous dimming and phase-shift dimming case) are set respectively at $10 \%, 50 \%$ and $80 \%$. In all scenarios, the LED currents are precisely controlled based on their respective dimming control parameters. Additionally, all the LED currents have a PWM frequency of $200 \mathrm{~Hz}$ and are not pulsating at a high frequency. Importantly, the LED driver is operating normally even though the dimming switches are overlapping with one another.

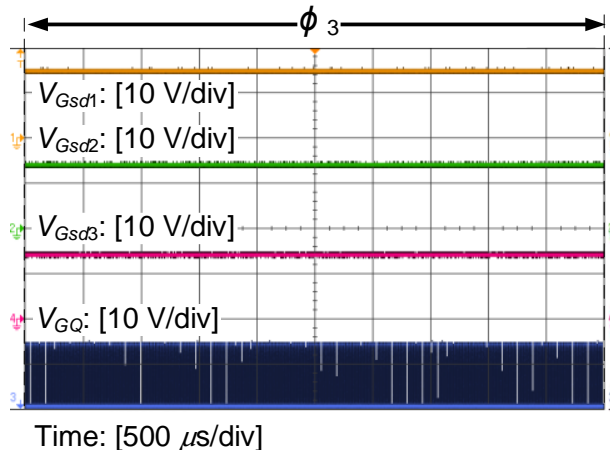

(a)

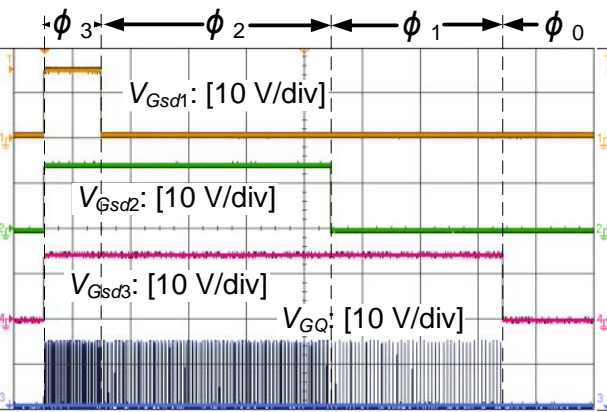

Time: $[500 \mu \mathrm{s} / \mathrm{div}]$

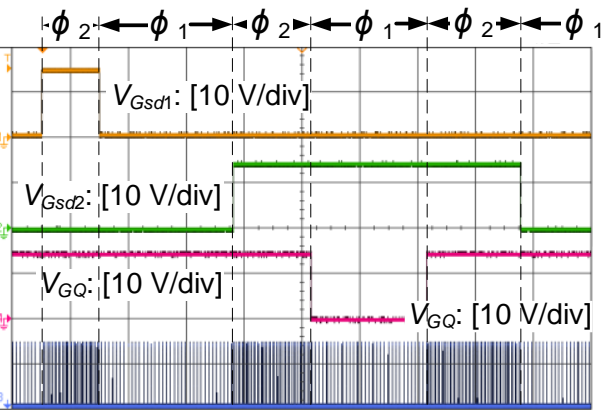

Time: $[500 \mu \mathrm{s} / \mathrm{div}]$

(b)

(c)

Fig. 19. The gate drive signals of the dimming switches $\left(S_{d 1}, S_{d 2}, S_{d 3}\right)$ and the main switch $Q$ of the proposed driver with (a) no PWM dimming; (b) synchronous PWM dimming; and (c) phase-shift PWM dimming.

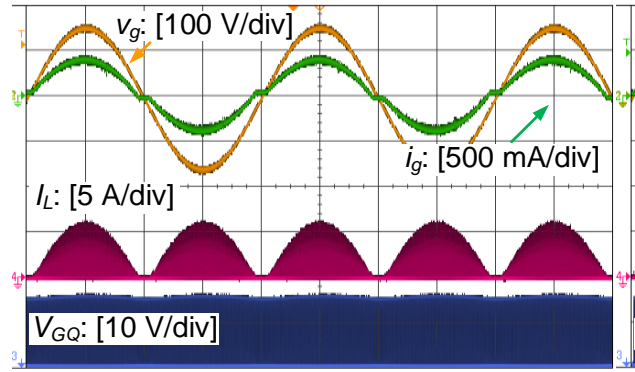

Time: [5 ms/div]

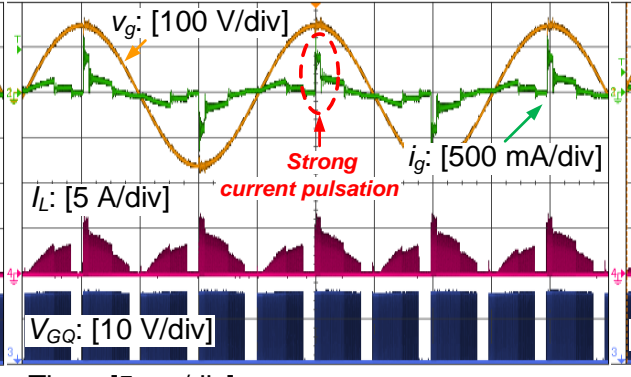

Time: [5 ms/div]

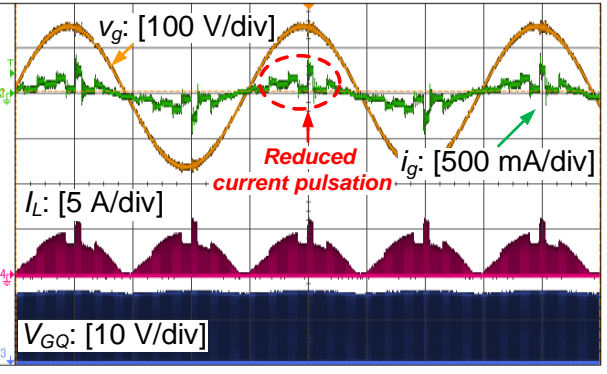

Time: [5 ms/div] 
Fig. 20. The measured input voltage, input current, inductor current and the gate signal for the main switch $Q$ of the proposed driver with (a) no PWM dimming; (b) synchronous PWM dimming; and (c) phase-shift PWM dimming.

Fig. 19 shows the experimental waveforms of the gate signals of the associated dimming switches $\left(S_{d 1}\right.$, $\left.S_{d 2}, S_{d 3}\right)$ and the main switch $Q$ corresponding to the operating waveforms given in Fig. 18. Fig. 19(a) shows that the LED driver is always operating in mode $\phi_{3}$ as the three power channels are always active. In contrast, in the cases depicted in Fig. 19(b) and (c), the LED driver is switching between modes $\phi_{0}-\phi_{3}$. This is notable by observing the color of the measured gate pulses for $Q$ in Fig. 19. A darker color means more power channels are activated during a switching period, while a lighter color means less power channels are enabled.

Interestingly, as the LED driver is switching between different operation modes, its instantaneous output power is also switching to different power levels. For instance, the LED driver outputs the highest power during $\phi_{3}$, while it outputs no power during $\phi_{0}$. The change of power demand is reflected through the number of inductor current pulses shown in Fig. 18 (darker means more pulses and vice versa). For synchronous dimming, the operation mode always starts with $\phi_{3}$ and ends with $\phi_{0}$ since the rising edges of the three dimming signals are synchronous. Therefore, with a synchronous dimming scheme, the LED driver must operate from no load (during $\phi_{0}$ ) to full load (during $\phi_{3}$ ) condition per dimming period. The input current $i_{g}$ which is a filtered version of the inductor current $i_{L}$ will thus be strongly pulsating between zero and a high current value (Fig. 20 (b)). The rich harmonic content in $i_{g}$ will severely deteriorate the power factor (PF) and the total harmonic distortion (THD) performance of the LED driver. In contrast, with the phase-shift dimming scheme, the instantaneous power is less pulsating. This is because the power demand is distributed more evenly along the time domain. According to Fig. 20(c), the LED driver is repeatedly switching between $\phi_{1}$ to $\phi_{2}$. The fluctuation of the power demand is clearly reduced as compared to that in the synchronous dimming case. Therefore, the input current becomes smoother and less pulsating (Fig. 20 (c)). 


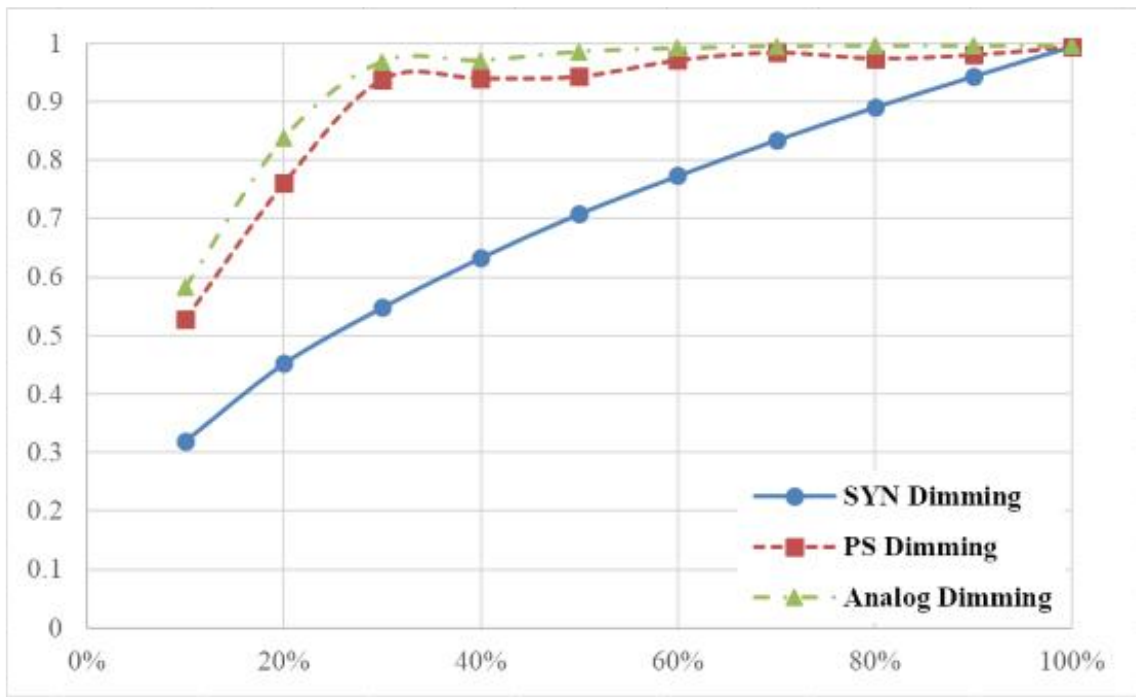

Fig. 21. Power factor comparison of the proposed driver with the analog dimming, synchronous PWM dimming and phase-shift PWM dimming.

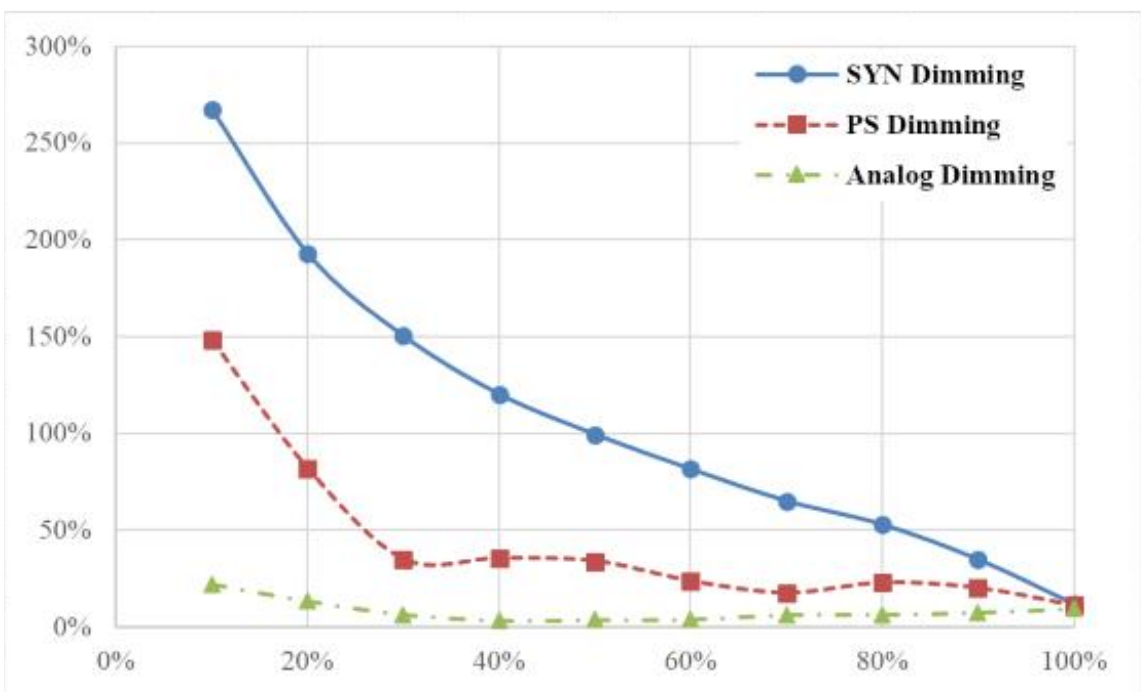

Fig. 22. THD comparison of the proposed driver with the analog dimming, synchronous PWM dimming and phase-shift PWM dimming.

The three system-level dimming schemes (analog dimming, synchronous PWM dimming and phase-shift PWM dimming) are further compared over their PF, THD and efficiency performance, of which the results are provided in Fig. 21-Fig. 23. In the comparison, the three LED strings are set to have identical dimming control parameters, i.e., the same ON-state current references and/or the same dimming ratios. For the two 
PWM dimming schemes, the ON-state current references are set at $360 \mathrm{~mA}$; while for the analog dimming, the full-load (100\%) currents for $I_{L E D 1}-I_{L E D 3}$ are set at $360 \mathrm{~mA}$.

Fig. 21 and Fig. 22 show that the PF and THD performances are better with the analog dimming than that with the two PWM dimming schemes. This is because the instantaneous power demand of a SIMO LED driver is continuous with analog dimming, while it is pulsating with a PWM dimming scheme. For both PWM dimming schemes, the PF decreases and the THD increases with the decrease of the dimming ratio. Nevertheless, it is shown that the phase-shift PWM dimming will always outperform the synchronous PWM dimming scheme regardless of the dimming ratio. Moreover, the PF performance with the phase-shift PWM dimming is quite similar to that of the analog dimming scheme. As shown in Fig. 21, even for a dimming ratio as low as 30\%, the PF with the phase-shift PWM dimming scheme is still higher than 0.9 and satisfies the Energy Star requirement [25]. It should be emphasized that the switching patterns of a PWM dimming are not limited to a phase-shift or a synchronous form. They might be further optimized such that low THD and high PF are achievable within the full dimming range.

Fig. 23 shows the measured efficiency of the proposed SIMO LED driver under the various dimming schemes. It is shown that the efficiency with both the PWM dimming schemes are relatively constant over the entire load condition. This is in contrast to that of the analog dimming, of which the efficiency tends to drop more significantly as the dimming ratios decreases. 


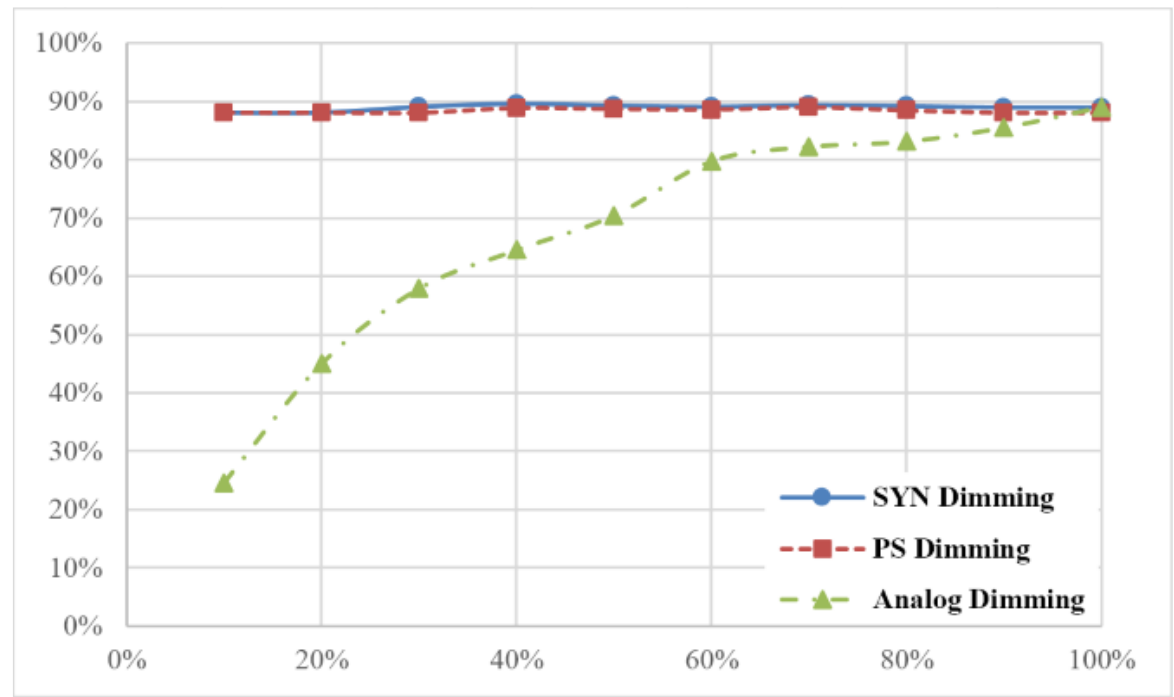

Fig. 23. Efficiency comparison of the proposed driver with the analog dimming, synchronous PWM dimming and phase-shift PWM dimming.

\section{CONCLUSIONS}

In this paper, an AC-powered SIMO LED driver with high performance and flexible dimming capability is proposed. To enable the PWM dimming capabilities for each output channel, additional dimming switches are inserted in series with each LED string. To achieve precise and full-range dimming, an instant-dutyrestoration technique and a coordinated low-frequency-and-time-sharing technique are proposed to tackle the fundamental dimming challenges at the string-level and at the system-level. Both simulation and experiment results prove that (i) precise dimming (ii) full range dimming and (iii) flexible string-level and system-level dimming can be achieved. Different dimming schemes have also been compared and analyzed over the PF, THD and energy efficiency performance. The phase-shift PWM dimming scheme seems to have the best overall system performance.

\section{REFERENCES}

[1] S. Beczkowski and S. Munk-Nielsen, "Led Spectral and Power Characteristics Under Hybrid PWM/AM Dimming Strategy," in 2010 IEEE Energy Conversion Congress and Exposition, 2010, pp. 731-735.

[2] K. H. Loo, Y. M. Lai, and C. K. Tse, "On Driving Techniques for LEDs: Toward a Generalized Methodology,” IEEE Trans. Power Electron., vol. 24, no. 12, pp. 2967-2976, Dec. 2009. 
[3] H.-T. Chen, S.-C. Tan, and S. Y. R. Hui, "Nonlinear Dimming and Correlated Color Temperature Control of Bicolor White LED Systems," IEEE Trans. Power Electron., vol. 30, no. 12, pp. 69346947, Dec. 2015.

[4] A. T. L. Lee, H. Chen, S.-C. Tan, and S. Y. R. Hui, "Precise Dimming and Color Control of LED Systems Based on Color Mixing," IEEE Trans. Power Electron., vol. 31, no. 1, pp. 65-80, Jan. 2016.

[5] Y. Hu and M. Jovanovic, "LED driver with self-adaptive drive voltage," IEEE Trans. Power Electron., vol. 23, no. 6, pp. 3116-3125, 2008.

[6] C.-H. Lin, T.-Y. Hung, C.-M. Wang, and K.-J. Pai, "A Balancing Strategy and Implementation of Current Equalizer for High Power LED Backlighting," in International Conference on Power Electronics and Drive Systems PEDS 2007, 2007, pp. 1613-1617.

[7] K. I. Hwu and Y. T. Yau, "Applying One-Comparator Counter-Based Sampling to Current Sharing Control of Multichannel LED Strings," IEEE Trans. Ind. Appl., vol. 47, no. 6, pp. 2413-2421, Nov. 2011.

[8] H. Ma, J.-S. Lai, Q. Feng, W. Yu, C. Zheng, and Z. Zhao, "A Novel Valley-Fill SEPIC-Derived Power Supply Without Electrolytic Capacitor for LED Lighting Application," IEEE Trans. Power Electron., vol. 27, no. 6, pp. 3057-3071, Jun. 2012.

[9] H. Wu, S. Ji, F. C. Lee, and X. Wu, "Multi-channel constant current (MC3) LLC resonant LED driver," in IEEE Energy Conversion Congress and Exposition, 2011, pp. 2568-2575.

[10] W. Chen and S. Y. R. Hui, "A Dimmable Light-Emitting Diode (LED) Driver With Mag-Amp Postregulators for Multistring Applications," IEEE Trans. Power Electron., vol. 26, no. 6, pp. 1714 1722, Jun. 2011.

[11] R. Zane, "LED Driver Circuit with Series-Input-Connected Converter Cells Operating in Continuous Conduction Mode," IEEE Trans. Power Electron., vol. 25, no. 3, pp. 574-582, Mar. 2010.

[12] Chang-Yu Wu, Tsai-Fu Wu, Jiun-Ren Tsai, Yaow-Ming Chen, and Chien-Chih Chen, "Multistring LED Backlight Driving System for LCD Panels With Color Sequential Display and Area Control," IEEE Trans. Ind. Electron., vol. 55, no. 10, pp. 3791-3800, Oct. 2008.

[13] Y. Guo, S. Li, A. Lee, S.-C. Tan, C. Lee, and S. Hui, "Single-Stage AC/DC Single-Inductor MultipleOutput LED Drivers," IEEE Trans. Power Electron., vol. PP, no. 99, pp. 1-1, 2015.

[14] P. K. T. Mok, "Single-inductor multiple-output switching converters with bipolar outputs," in ISCAS 2001. The 2001 IEEE International Symposium on Circuits and Systems (Cat. No.01CH37196), 2001, vol. 2, pp. 301-304.

[15] H. Chen, Y. Zhang, and D. Ma, "A SIMO Parallel-String Driver IC for Dimmable LED Backlighting With Local Bus Voltage Optimization and Single Time-Shared Regulation Loop," IEEE Trans. Power Electron., vol. 27, no. 1, pp. 452-462, Jan. 2012.

[16] A. T. L. Lee, J. K. O. Sin, and P. C. H. Chan, "Scalability of Quasi-Hysteretic FSM-Based Digitally Controlled Single-Inductor Dual-String Buck LED Driver to Multiple Strings," IEEE Trans. Power Electron., vol. 29, no. 1, pp. 501-513, Jan. 2014.

[17] F. C. Lee and P. Mattavelli, "Optimal Trajectory Control of LLC Resonant Converters for LED PWM Dimming,” IEEE Trans. Power Electron., vol. 29, no. 2, pp. 979-987, Feb. 2014. 
[18] D. Gacio, J. M. Alonso, J. Garcia, L. Campa, M. J. Crespo, and M. Rico-Secades, "PWM Series Dimming for Slow-Dynamics HPF LED Drivers : the High-Frequency Approach," IEEE Trans. Ind. Electron., vol. 59, no. 4, pp. 1717-1727, Apr. 2012.

[19] L. Lohaus, A. Rossius, S. Dietrich, R. Wunderlich, and S. Heinen, "A Dimmable LED Driver With Resistive DAC Feedback Control for Adaptive Voltage Regulation," IEEE Trans. Ind. Appl., vol. 51, no. 4, pp. 3254-3262, Jul. 2015.

[20] Yu-Kang Lo, Kuan-Hung Wu, Kai-Jun Pai, and Huang-Jen Chiu, "Design and Implementation of RGB LED Drivers for LCD Backlight Modules," IEEE Trans. Ind. Electron., vol. 56, no. 12, pp. 4862-4871, Dec. 2009.

[21] M. Doshi and R. Zane, "Digital Architecture for Driving Large LED Arrays with Dynamic Bus Voltage Regulation and Phase Shifted PWM," in APEC 07 - Twenty-Second Annual IEEE Applied Power Electronics Conference and Exposition, 2007, pp. 287-293.

[22] C.-C. Chen, C.-Y. Wu, Y.-M. Chen, and T.-F. Wu, "Sequential Color LED Backlight Driving System for LCD Panels," IEEE Trans. Power Electron., vol. 22, no. 3, pp. 919-925, May 2007.

[23] C.-C. Chen, C.-Y. Wu, and T.-F. Wu, "Fast Transition Current-Type Burst-Mode Dimming Control for the LED Back-Light Driving System of LCD TV," in 37th IEEE Power Electronics Specialists Conference, 2006, pp. 1-7.

[24] B. Lehman, A. Wilkins, S. Berman, M. Poplawski, and N. Johnson Miller, "Proposing measures of flicker in the low frequencies for lighting applications," in IEEE Energy Conversion Congress and Exposition, 2011, pp. 2865-2872.

[25] "ENERGY STAR Program Requirements for Solid State Lighting Luminaires, Eligibility Criteria Version 1.1," 2008. [Online]. Available:

http://www.energystar.gov/index.cfm?c=new_specs.ssl_luminaires. 